\title{
Echocardiographic Assessment of Epicardial Adipose Tissue - A Marker of Visceral Adiposity
}

\author{
Navneet Singh*, Harleen Singh, Harleen K Khanijoun, Gianluca Iacobellis
}

\begin{abstract}
Visceral adipose tissue predicts an unfavorable cardiovascular and metabolic risk profile in humans. Existing methods to assess visceral adipose tissue have been limited. Thus, echocardiographic assessment of epicardial adipose tissue as a marker of visceral adiposity was suggested. The technique has been shown to be a very reliable method and an excellent measure of visceral adiposity. In this article, epicardial adipose tissue's localization on the heart, function, method of assessment and reliability as a marker of visceral adiposity is briefly reviewed. Areas of the technique requiring further study are identified.
\end{abstract}

KEYWORDS: epicardial adipose tissue, echocardiography, obesity, body-mass index, visceral adiposity

\section{INTRODUCTION}

Metabolic and cardiovascular diseases are well known to be more prevalent in obese individuals than non-obese individuals (1). More specifically, increased visceral adipose tissue, the fat that surrounds the internal organs (e.g., heart, intestines) in the cavities of the body, predicts an unfavorable cardiovascular and metabolic risk profile (1-5). For example, visceral adiposity is strongly correlated with diabetogenic features (e.g., impaired insulin sensitivity, increased insulin levels), atherogenic features (e.g., increased triglycerides, decreased high density lipoproteins), prothrombotic factors (e.g., increased fibrinogen, Factor VII, plasminogen activator inhibitor 1) and proinflammatory cytokines (e.g., interleukin-6 [IL-6] and tumour necrosis factor-a [TNF- a]) (1-5).

*To whom correspondence should be addressed:

Naveet Singh, BHSc Hon, 1TO (Toronto MD , Class 2010), Cardiovascular Obesity Research \& Management, McMaster General Hospital, 237 Barton Street East, Hamilton, L8L 2X2 Tel: +1-07-527-4322

Fax: +1-907-522-4538

Email: navneet.singh@utoronto.ca
A significant interest lies in reliably quantifying adipose tissue. Quantifying visceral adipose tissue accurately and reliably allows for better cardiovascular and metabolic risk stratification of patients and may be beneficial at the community level. Visceral adipose tissue quantification may also serve to measure the effectiveness of pharmacotherapy or physical activity regimens in targeting visceral adipose tissue, thus serving as a therapeutic endpoint.

Various methods to quantify visceral adipose tissue directly by expensive magnetic resonance imaging and radiation-exposing computed tomography, as well as indirectly by anthropometric measures (e.g., waistcircumference, body-mass index) exist (6-9, 27). Magnetic resonance imaging is the gold standard technique to accurately measure visceral adiposity although there is some concern about the accuracy of actual visceral adiposity content based on single slice sampling (i.e., whole body magnetic resonance imaging scan is the true gold standard) $(7,10)$. Waistcircumference as measure of visceral obesity may be less reliable in older persons $(11,12)$. Also, waist- 
circumference may be a better measure of subcutaneous rather than visceral obesity $(11,12)$. Anthropometric techniques requiring measurement of the waist (e.g., waist-circumference, waist-to-hip ratio) may not account for possibly confounding subcutaneous adipose tissue especially in more obese individuals though waist circumference is considered an accepted measure of intra-abdominal adiposity $(11,12,13)$. Body-mass index, an anthropometric measure of visceral adiposity is suggested to be a poorer indicator of cardiovascular risk than waist-circumference across ethnicities, suggesting that body-mass index may not be a very good measure of visceral obesity (14).

In light of the limitations, lack of practicality of existing methods and the recognition that more reliable measures of visceral adiposity are needed, Iacobellis et al. proposed the direct measurement of epicardial adipose tissue thickness via echocardiography as a marker for visceral adiposity (15).

In this article, we review epicardial adipose tissue's basic characteristics, method of clinical assessment, and reliability in measuring visceral adiposity, as well as identify areas that need further study.

\section{STRUCTURE AND FUNCTION OF EPICARDIAL} ADIPOSE TISSUE

Adapted from a recent review on epicardial adipose tissue's relationship with the heart, Figure 1 illustrates the macroscopic appearance of adipose tissue on a normal and hypertrophied heart (16). Typically, normal fat distributions in the heart are restricted to the grooves between the atrium and ventricles, between the ventricles and along the coronary arteries (16). As the
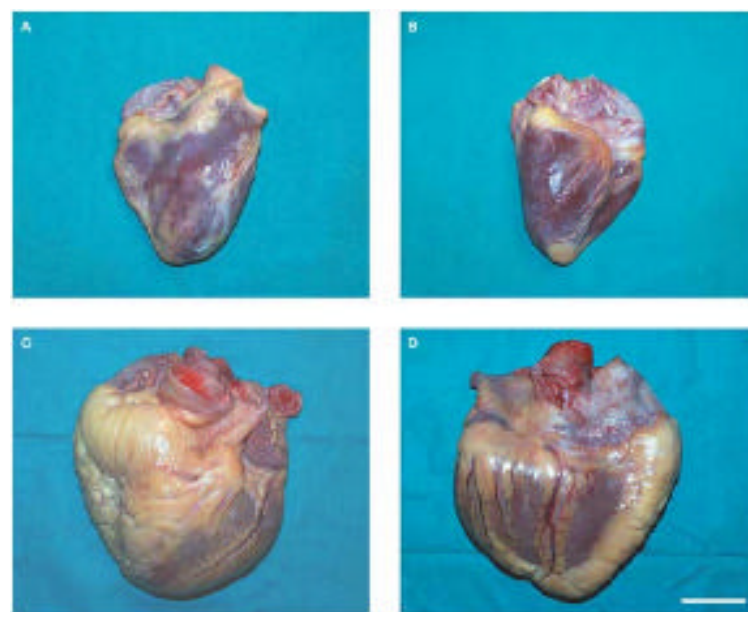

Figure 1: Macroscopic appearance of epicardial fat (A) Anterior view of a normal (210 g) heart. (B) Posterior view of a normal (210 g) heart. (C) Anterior view of a hypertrophic $(900$ g) heart. (D) Posterior view of a hypertrophic (900 g) heart. Scale: bar $=4 \mathrm{~cm}$.

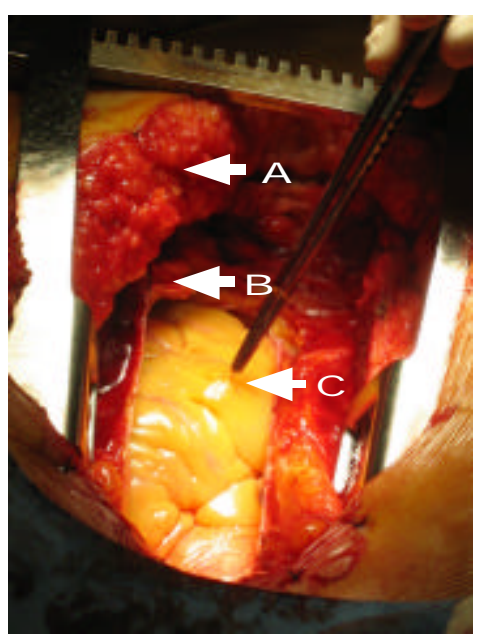

Figure 2: Exposed heart in an obese individual undergoing a triple coronary artery bypass.

(A) Adipose tissue deposited in the chest under the skin ( subcutaneous). (B) Pericardial tissue. (C) Epicardial adipose tissue pulled up by forceps (the adipose tissue abnormally covers entire heart in this patient).

mass of epicardial adipose tissue increases, the ventricular surfaces become covered with adipose tissue (16). Figure 2 shows the massive amount of epicardial adipose tissue that is deposited between the pericardium and heart in an obese patient undergoing coronary artery bypass.

Epicardial adipose tissue is suspected to directly interact with the adjacent myocardial tissue. Both tissues share the same coronary blood supply and no fascia-like structure separates the epicardial adipose tissue from myocardium (17).

The specific function of epicardial adipose tissue is yet to be determined though it is known to be very active (e.g., considered a secretory organ) (18). The tissue is not known to serve to protect the heart from blunt trauma (16). Interestingly, though the tissue is thought to be important, the tissue does not exist in laboratory mice or rats (19). Marchington's animal experimental studies showed that the principle difference between epicardial adipose tissue and other visceral adipose tissues is its greater capacity for free fatty acid release (19). Thus, epicardial adipose tissue may act as a local energy supply for the myocardium or buffer against toxic levels of free fatty acids (19).

Epicardial adipose tissue is a very active endocrine organ and may have an effect on local coronary artery health. For example, epicardial adipose tissue is shown to express various inflammatory factors such as IL1beta, IL-6, MCP-1 (Monocyte chemotactic protein-1), and TNF-alpha mRNA in high risk cardiac patients (e.g., coronary artery disease) $(20,21)$. The tissue also secretes adiponectin, a serum protein known to be secreted exclusively by adipose tissues, with antiinflammatory and anti-atherogenic properties $(18,22)$. However, adiponectin secretion is markedly decreased in patients with coronary artery disease compared to those patients without the disease (23).

Increases in epicardial adipose tissue seem to be 
associated with abnormal cardiac morphology. Studies show that epicardial adipose tissue is associated with increased ventricular mass (17). A recent study we conducted also demonstrates that atria enlargement and impairment in diastolic filling is associated with epicardial adipose tissue in morbidly obese subjects (24).

\section{ECHOCARDIOGRAPHIC ASSESSMENT OF EPICARDIAL ADIPOSE TISSUE}

Epicardial fat thickness is measured on the free wall of the right ventricle from both parasternal long- and short-axis views (Figure 3) (15). The largest amount of epicardial fat is usually seen at this right ventricular free wall site. Epicardial adipose tissue is usually seen as an echo-free or if it is massive, hyper-echoic space. It is important to ensure that epicardial fat thickness is not measured obliquely since it falsely increases measurements. Since there is some variation in the longitudinal thickness of epicardial fat, three measurements are usually taken and averaged in various research studies that demonstrate the reliability of epicardial fat thickness as a marker of visceral adiposity. The reliability of epicardial adipose tissue thickness on the free wall of the right ventricle is good when comparing with baseline magnetic resonance imaging (25).

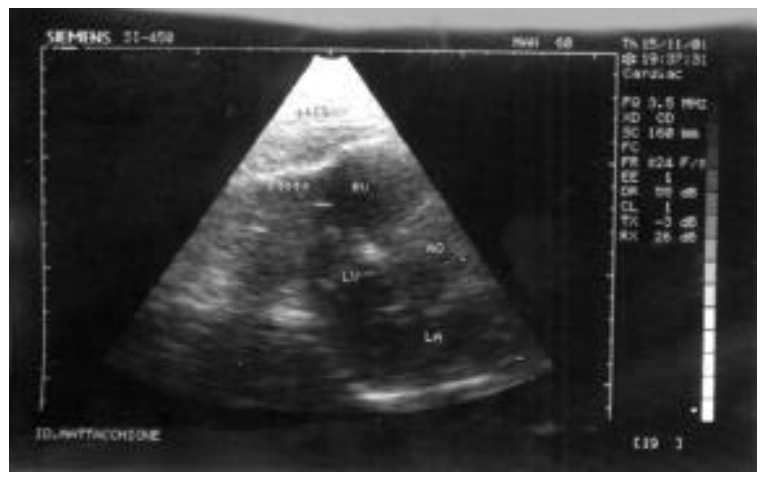

Figure 3: Transthoracic echocardiogram (para-sternal long view) showing a large area of epicardial adipose tissue (arrows) on free wall of right ventricle.

Echocardiography is non-invasive and safe. It is also relatively cost and time efficient since it may be part of the routine assessment that patients suspected to be at risk for cardiovascular or metabolic illness undergo. Only very few limitations exist. First, though epicardial adipose tissue thickness is not as clearly measured as in magnetic resonance imaging, as already mentioned, the method is highly reliable. Second, at times it is possible to confuse pericardial fluid with adipose tissue since the fluid also shows up as relatively echo-free on an echocardiograph (15).

\section{EPICARDIAL ADIPOSE TISSUE'S RELIABILITY AS A MARKER OF VISCERAL ADIPOSITY}

Several studies have demonstrated the reliability of epicardial adipose tissue's thickness measurement via echocardiography as a marker for visceral adiposity (and the related metabolic and cardiovascular risk) (15, 17, 20, 24-27). Epicardial adipose tissue has been shown to be very closely related to intra-abdominal adiposity, a marker of entire body visceral adiposity, according to various magnetic resonance imaging studies $(15,20)$. For example, an excellent correlation between epicardial adipose tissue and waist circumference $(r=0.895, p=0.01)$ and magnetic resonance image abdominal visceral adipose tissue $(r=$ $0.864, \mathrm{p}=0.01$ ) is reported (15). In the same study, multiple regression analysis showed that epicardial adipose tissue thickness was the strongest independent variable correlated to magnetic resonance image visceral adipose tissue $(\mathrm{r} 2=0.442, \mathrm{p}=0.02)(15)$.

Visceral adiposity is associated with features of cardiovascular risk profile and metabolic syndrome (2527). Epicardial fat thickness has been shown to be directly associated with many of these features that include increased LDL cholesterol, fasting insulin ( $\mathrm{r} 2=$ 0.387; $\mathrm{P}=0.03)$, left ventricular mass $(\mathrm{r}=0.755, \mathrm{p}=$ $0.01)$ and diastolic blood pressure $(\mathrm{r} 2=0.387 ; \mathrm{P}=$ $0.02)$, as well as decreased adiponectin $(25,26)$.

Furthermore, waist-circumference, considered a good indicator of visceral adiposity, is confounded by subcutaneous abdominal fat thickness (28). It is well known that visceral adiposity rather than subcutaneous adiposity is more responsible for the health risks associated with fat deposition in humans (29). Epicardial adipose tissue measurements are not confounded by sub-cutaneous fat (16). Thus, given the poor reliability of waist circumference as a measure of visceral adiposity, echocardiographic measurement of visceral adipose tissue likely provides a truer visceral fat content estimate.

\section{FURTHER STUDY}

The epicardial adipose tissue measurement via echocardiography technique to predict visceral adiposity and their associated health risks is relatively young (the technique was suggested in 2003). Thus far, various studies suggest it is an extremely useful and effective method, and one that is increasingly important as more and more anatomic, bimolecular, and clinical relationships are found with epicardial adipose tissue (26). Nevertheless, various questions remain unanswered or are in the process of being answered in various studies we are conducting.

The use of the technique to measure epicardial adipose tissue thickness, as well as the relationship between 
epicardial adipose tissue thickness and health risks, has been mostly limited to European-Caucasian subjects. Whether or not epicardial adipose tissue allows for prediction of cardiometabolic alterations in noncaucasian subjects remains to be determined.

The use of epicardial adipose tissue thickness as measured by echocardiography as an effective therapeutic or physical health endpoint remains to be determined. Often, exercise regimens may not decrease a person's weight or "fatty" appearance. Physical activity is shown to promote fat catabolism and muscle anabolism (one reason for the constant weight). Secondly, it is the visceral adiposity that is the important marker of "health risks". Indeed, measuring epicardial adipose tissue, a marker of visceral adiposity, may be more important than using change in weight or a less reliable measure of visceral adiposity as a marker of cardiometabolic fitness.

Many questions remain about the molecular relationships of epicardial adipose tissue that may support the importance of measuring epicardial adipose tissue thickness. Additionally, studies on the relationship of thickness of epicardial adipose tissue to secretion of adipocytokines are limited (30-31).

Finally, various additional questions remain that will be answered as further studies regarding epicardial adipose tissue are conducted, including the reliability of the echocardiographic technique between users and the ability for widespread use of the techique.

\section{ACKNOWLEDGEMENTS}

NS was supported by Dr. Arya M. Sharma, Cardiovascular Obesity Research and Management at Hamilton General Hospital, and the Heart and Stroke Foundation JD Schultz Scholarship at the time of writing this article.

\section{REFERENCES}

1. Despres JP. Is Visceral Obesity the Cause of the Metabolic Syndrome? Ann Med 2006; 38: 52-63.

2. Miller WM, Nori-Janosz KE, Lillystone M, McCullough PA. Obesity and Lipids. Curr Cardiol Rep 2005; 7: 465-470.

3. Chan JC, Tong PC, Critchley JA. The Insulin Resistance Syndrome: Mechanisms of Clustering of Cardiovascular Risk. Semin Vasc Med 2002; 2: 45-57.

4. Ross R, Freeman J, Hudson R, Janssen I. Abdominal Obesity, Muscle Composition, and Insulin Resistance in Premenopausal Women. J Endocrinol 2002; 87: 5044-5051.

5. Taguchi R, Takasu J, Itani Y, et al. Pericardial Fat Accumulation in Men as a Risk Factor for Coronary Artery Disease. Atherosclerosis 2001; 157: 203-209.

6. Ross R, Shaw KD, Martel Y, de Guise J, Avruch L. Adipose Tissue Distribution Measured by Magnetic Resonance Imaging in Obese Women. Am J Clin Nutr 1993; 57: 470-475.

7. Ross RL, Leger D, Morris D, de Guise J, Guardo R. Quantification of Adipose Tissue by MRI: Relationship with Anthropometric Variables. J Appl Physiol 1992; 72: 787-795.

8. Gronemeyer SA, Steen RG, Kauffman WM, Reddick WE, Glass JO. Fat Adipose Tissue (FAT) Assessment by MRI. Magn Reson
Imaging 2000; 18: 815-818.

9. Wei M, Gaskill SP, Haffner SM, Stern MP. Waist Circumference as the Best Predictor of Noninsulin Dependent Diabetes Mellitus (NIDDM) Compared to Body Mass Index, Waist/hip Ratio and Other Anthropometric Measurements in Mexican Americans--a 7-year Prospective Study. Obes Res 1997; 5: 16-23.

10. Thomas EL, Saeed N, Hajnal JV, Brynes A, Goldstone AP, Frost G, Bell JD. Magnetic Resonance Imaging of Total Body Fat. J Appl Physiol 1998; 85: 1778-1785.

11. Bonora E, Micciolo R, Ghiatas AA, et al. Is it Possible to Derive a Reliable Estimate of Human Visceral and Subcutaneous Abdominal Adipose Tissue from Simple Anthropometric Measurements? Metabolism 1995; 44: 1617-1625.

12. Iwao S, Iwao N, Muller DC, Elahi D, Shimokata H, Andres R. Does Waist Circumference Add to the Predictive Power of the Body Mass Index for Coronary Risk? Obes Res 2001; 9: 685695.

13. Kamel EG, Mcneill G, Van Wijk MC. Usefulness of Anthropometry and DXA in Predicting Intra-abdominal Fat in Obese Men and Women. Obes Res 2000; 8: 36-42.

14. Yusuf $S$, Hawken $S$, Ounpuu S, et al. Obesity and the Risk of Myocardial Infarction in 27,000 Participants from 52 Countries: a Case-control Study. Lancet 2005; 5: 1640-1649.

15. Iacobellis G, Assael F, Ribaudo MC, et al. Epicardial Fat from Echocardiography: a New Method for Visceral Adipose Tissue Prediction. Obes Res 2003; 11: 304-310.

16. Iacobellis G, Corradi D, Sharma AM. Epicardial Adipose Tissue: Anatomic, Biomolecular and Clinical Relationships with the Heart. Nat Clin Pract Cardiovasc Med 2005; 2: 536-543.

17. Corradi D, Maestri R, Callegari $S$, et al. The Ventricular Epicardial Fat is Related to the Myocardial Mass in Normal, Ischemic and Hypertrophic Hearts. Cardiovasc Pathol 2004; 13: 313-316.

18. Okamoto Y, Arita Y, Nishida M, et al. An Adipocyte-derived Plasma Protein, Adiponectin, Adheres to Injured Vascular Walls. Horm Metab Res 2000; 32: 47-50.

19. Marchington JM, Mattacks CA, Pond CM. Adipose Tissue in the Mammalian Heart and Pericardium: Structure, Fetal Development and Biochemical Properties. Comp Biochem Physiol B 1989; 94: 225-232

20. Mazurek T, Zhang L, Zalewski A, et al. Human Epicardial Adipose Tissue is a Source of Inflammatory Mediators. Circulation 2003; 108: 2460-2466.

21. Baker AR, Silva NF, Quinn DW, et al. Human Epicardial Adipose Tissue Expresses a Pathogenic Profile of Adipocytokines in Patients with Cardiovascular Disease. Cardiovasc Diabetol 2006; 13: 1.

22. Arita Y, Kihara S, Ouchi N, et al. Adipocyte-derived Plasma Protein Adiponectin acts as a Platelet-derived Growth FactorBB-binding Protein and Regulates Growth Factor-induced Common Postreceptor Signal in Vascular Smooth Muscle Cell. Circulation 2002; 105: 2893-2898.

23. Iacobellis G, Pistilli D, Gucciardo $M$, et al. Adiponectin Expression in Human Epicardial Adipose Tissue in Vivo is Lower in Patients with Coronary Artery Disease. Cytokine 2005; 29: 251-255.

24. Iacobellis G, Leonetti F, Singh N, Sharma AM. Relationship of Epicardial Adipose Tissue with Atrial Dimensions and Diastolic Function in Morbidly Obese Subjects. Int J Cardiol 2006; In Press.

25. Iacobellis G, Ribaudo MC, Assael F, et al. Echocardiographic Epicardial Adipose Tissue is Related to Anthropometric and Clinical Parameters of Metabolic Syndrome: a New Indicator of Cardiovascular Risk. J Clin Endocrinol Metab 2003; 88: 51635168.

26. Iacobellis G, Ribaudo MC, Zappaterreno A, Iannucci CV, Leonetti F. Relation between Epicardial Adipose Tissue and Left 
Ventricular Mass. Am J Cardiol 2004; 94: 1084-1087.

27. Wheeler GL, Shi R, Beck SR, et al. Pericardial and Visceral Adipose Tissues Measured Volumetrically with Computed Tomography are Highly Associated in Type 2 Diabetic Families. Invest Radiol 2005; 40: 97-101.

28. Maurovich-Horvat P, Massaro J, Fox CS, et al. Comparison of Anthropometric, Area- and Volume-based Assessment of Abdominal Subcutaneous and Visceral Adipose Tissue Volumes using Multi-detector Computed Tomography. Int J Obes (Lond) 2006; Sep 5 [Epub ahead of print].

29. Sharma AM. Adipose Tissue: a Mediator of Cardiovascular Risk. Int J Obes Relat Metab Disord 2002; 4: S5-7.

30. Baker AR, Silva NF, Quinn DW, et al. Human Epicardial Adipose Tissue Expresses a Pathogenic Profile of Adipocytokines in Patients with Cardiovascular Disease. Cardiovasc Diabetol 2006; 13(5): 1.

31. Iacobellis G, Pistilli D, Gucciardo M, et al. Adiponectin Expression in Human Epicardial Adipose Tissue in Vivo is Lower in Patients with Coronary Artery Disease. Cytokine 2005; 29: 251-255.

Navneet Singh, a graduate of the BHSc Program at McMaster University, is a first year medical student and co-chair of the Canadian Obesity Network Students and New Professionals group at the University of Toronto. His research interests include obesity and medical imaging.

Harleen Singh is a kinesiology student at McMaster University with research interests in cardiology and physical development.

Harleen K Khanijoun, a biomedical engineering graduate, is currently a Juris Doctor candidate at the University of Alabama pursuing intellectual property law. Her research interests include advances in bioinstrumentation.

Dr. Gianluca Iacobellis is an associate professor in endocrinology in the department of medicine at McMaster University. His research interests focus on the diagnostic, pathogenic and cardiovascular aspects of obesity and metabolic syndrome. He has authored and co-authored more than 40 peer-reviewed papers and 10 textbooks. 